\title{
Pendeteksi Tingkat Kebisingan berbasis Internet of Things sebagai Media Kontrol Kenyamanan Ruangan Perpustakaan
}

\author{
Arif Dwi Hidayat, Bambang Sudibya, Catur Budi Waluyo* \\ Departemen Teknik Elektro, Sekolah Tinggi Teknologi Adisutjipto, Yogyakarta \\ * email: catur_budiwaluyo@yahoo.co.uk
}

\begin{abstract}
The library is a place that is used as a study and reading room, so that a comfortable place is needed from disturbances in the library building. Based on the decision of the Minister of Environment in 1996, the standard noise for library environments ranged from 45 to $55 \mathrm{~dB}$. but in fact there is often a commotion caused by visitors. in this study a noise level detection system was created where the noise detection system is expected to be used as a media for comfort control in the library room. The noise level detector uses a sound sensor that is connected to Arduino. The system will be equipped with a warning system in the form of Buzzer and Warning Text sounds that will be displayed on the P1O LED Panel and equipped with Internet of Things technology that allows the supervisor or guard of the library to monitor the noise of the library room real time via Web Server. The test results show that this tool can detect noise levels in the range of at least $41 \mathrm{~dB}$ and a maximum of $69 \mathrm{~dB}$ with a deviation of 0.6 and an average error of $1.0 \%$. the average sound intensity measured in the library room is $56.24 \mathrm{~dB}$. The average percentage of the success of the system against Buzzer and Warning text warnings is equal to $97.3 \%$ and the average percentage of the success of sending data to the web server in the noise level detector is $95 \%$.
\end{abstract}

Keywords — Sound sensor, Internet of things, Web server, Level detection library noise.

\section{Pendahuluan}

Perpustakaan merupakan suatu tempat yang digunakan sebagai ruang belajar dan membaca, sehingga diperlukan tempat yang nyaman dari gangguan-gangguan yang ada di ruangan perpustakaan. Kebisingan pada perpustakaan masih sering terjadi, terutama berasal dari pengunjung itu sendiri. Petugas perpustakaan sudah melakukan upaya untuk mengatasi hal demikian, antara lain dengan memperingatkan pengunjung yang membuat keributan (kebisingan), akan tetapi petugas perpustakaan tentu tidak setiap waktu selalu memperingatkan atau mengontrol keadaan karena keterbatasan tenaga dan lain-lain.

Berdasarkan pada keputusan Menteri Lingkungan Hidup tahun 1996, bahwa standar kebisingan lingkungan perpustakaan berkisar 45-55 dB. Ruangan perpustakaan dikategorikan normal apabila intensitas suara berkisar pada range 45-55 dB. Namun, pada kenyataannya sering terjadi kegaduhan yang ditimbulkan oleh pengunjung yang melebihi dari nilai ambang batas yang telah ditentukan. Hal ini tentunya akan sangat mengganggu kenyamanan karena dengan kenyamanan konsentrasi pikiran akan senantiasa terjaga, sehingga membuat aktivitas membaca kurang berjalan maksimal.

\subsection{Kajian Pustaka}

Penelitian oleh Kharis pada tahun 2013 dengan judul "Rancang Bangun Sistem Deteksi Kebisingan Sebagai Media Kontrol Kenyamanan Ruangan Perpustakaan." Penelitian ini berisi tentang bagaimana menampilkan peringatan dalam bentuk tulisan pada Dot Matrix LED dan bunyi yang dihasilkan dari buzzer, apabila sistem mendeteksi kebisingan yang melebihi nilai ambang batas (NAB) kebisingan perpustakaan sebesar $55 \mathrm{~dB}$. 
Penelitian oleh Kurniawan pada tahun 2016 dengan judul "Purwa Rupa IoT (Internet of Things) Kendali Lampu Gedung" penelitian ini berisi tentang cara membangun sebuah perangkat kendali jarak jauh yang memanfaatkan TCP/IP untuk melakukan proses kendali dalam jaringan lokal melalui web server yang ditanamkan ke dalam perangkat kendali jarak jauh untuk mengendalikan lampu.

\subsection{Landasan Teori}

Adapun beberapa dasar teori untuk mendukung penelitian ini.

\section{A. Internet of Things}

IoT (Internet of Things) adalah jaringan dari benda-benda fisik yang tertanam dengan elektronik, perangkat lunak, sensor, dan konektivitas jaringan, yang memungkinkan bendabenda mengumpulkan data dan pertukaran data. IoT memungkinkan objek dikendalikan jarak jauh di infrastruktur jaringan yang ada. Ilustrasi dari jaringan IoT dilihat pada Gambar 1.

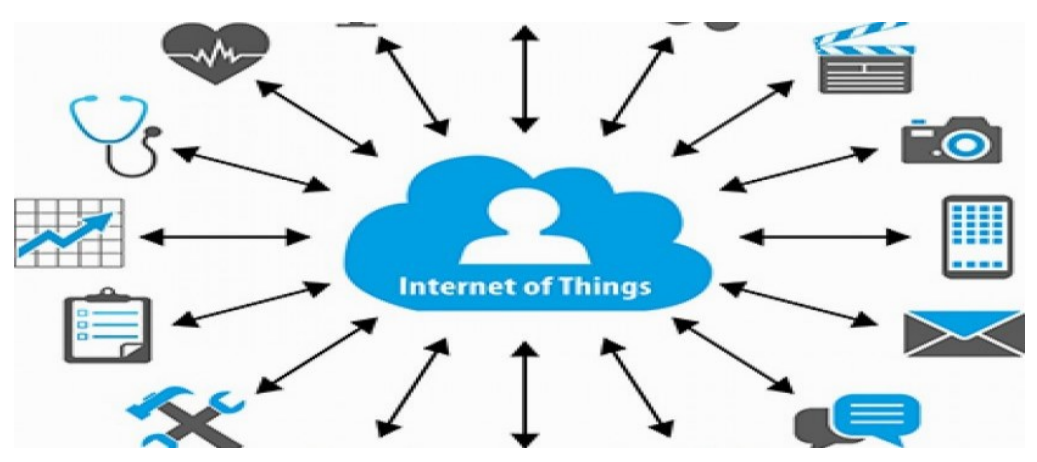

Gambar 1. Ilustrasi dari Jaringan IoT

\section{B. Tingkat Kebisingan Suara}

Sebagai panca indera yang berfungsi menangkap suara, telinga memiliki batas maksimal suara yang dapat ditolerir agar kesehatan telinga tetap terjaga. Beragamnya suara yang masuk ke telinga setiap hari secara tidak disadari memiliki potensi untuk menurunkan kualitas pendengaran. Maka, agar indera pendengaran senantiasa terjaga, perlunya mengetahui ambang batas pendengaran yang dapat ditolerir oleh telinga. Umumnya, suara dengan intensitas 30-50 $\mathrm{dB}$ adalah suara yang aman untuk didengar oleh telinga manusia, contohnya seperti suara orang yang sedang bercakap-cakap. Satuan ukuran untuk intensitas suara ialah dB. Telinga akan terasa sakit jika mendengar suara lebih dari $90 \mathrm{~dB}$.

\section{Condensor Mic}

Condensor atau kapasitor yaitu sebuah komponen elektronik yang menyimpan energi dalam bentuk medan elektrostatik. Mikrofon kondensor membutuhkan daya dari baterai ataupun sumber eksternal lain. Sinyal audio yang dihasilkan lebih kuat dibandingkan mikrofon dinamis. Karena cenderung lebih sensitif dan responsif dibanding mikrofon dinamis, maka mikrofon kondensor lebih cocok untuk menangkap detail-detail kecil pada suara. Sebaliknya mikrofon ini tidak ideal bekerja pada volume tinggi karena tingkat sensitifitasnya rentan terhadap distorsi, blok diagram dari Condensor Mic dapat dilihat pada Gambar 2. 


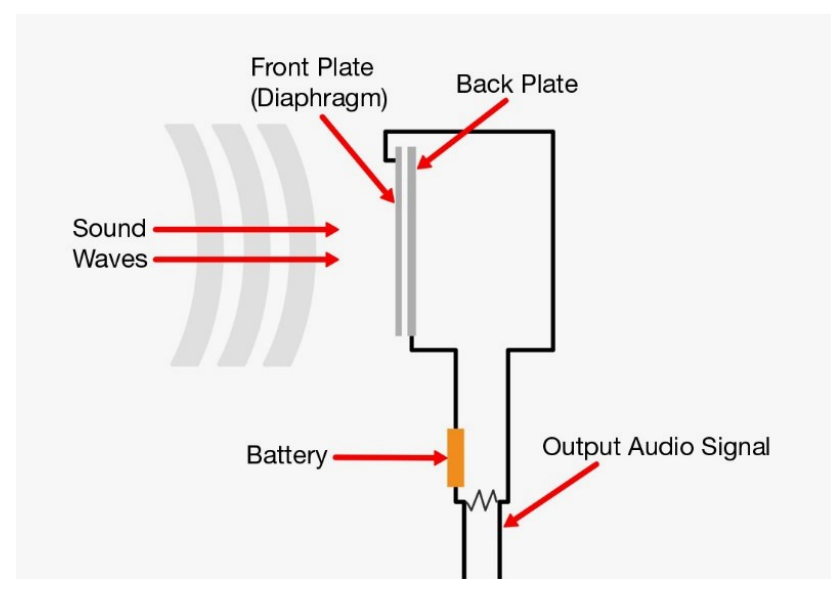

Gambar 2. Blok Diagram dari CondensorMic

Cara kerja dari sensor suara yaitu sebuah kapasitor terdiri dari dua buah plat dengan tegangan listrik di antara keduanya. Pada Condensor Mic, salah satu plat terbuat dari material yang sangat ringan dan berfungsi sebagai difragma. Ketika terkena gelombang suara, plat diafragma ini akan bergetar menyebabkan terjadinya perubahan jarak antar kedua plat sehingga menyebabkan terjadinya perubahan kapasitansi. Lebih jelas, ketika kedua plat saling merapat, kapasitansi akan meningkat dan terjadi penambahan arus. Ketika kedua plat saling menjauh, kapasitansi akan berkurang dan terjadi pelepasan arus. Agar kapasitor bekerja, dibutuhkan teganggan listrik yang berasal dari sumber Arduino. Skematik Condensor Mic dapat dilihat pada Gambar 3.

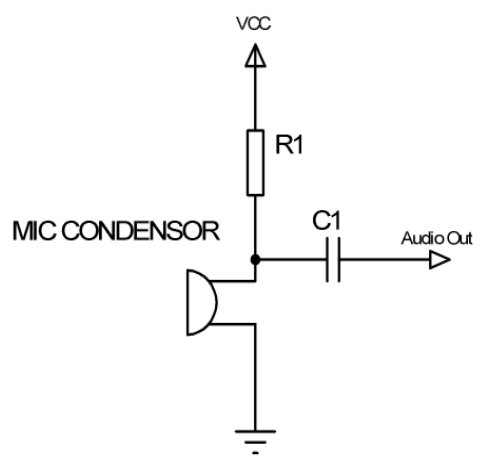

Gambar 3. Skematik Condensor Mic

\section{Web Server}

Web server adalah sebuah layanan berbasis data dan berfungsi menerima permintaan dari HTTP (Hyper Text TransferProtocol) atau HTTPS (Hyper Text Transfer Protocol Secure) pada klienyang biasa dikenal dengan nama web browser dan untuk mengirimkan kembali yang hasilnya dalam bentuk beberapa halaman web yang pada umumnya berbentuk dokumen HTML. Sederhananya web server akan mengirim data HTML kepada peminta web browser sehingga akan terlihat seperti umumnya yaitu sebuah tampilan website. Ilustrasi web server dilihat pada Gambar 4. 


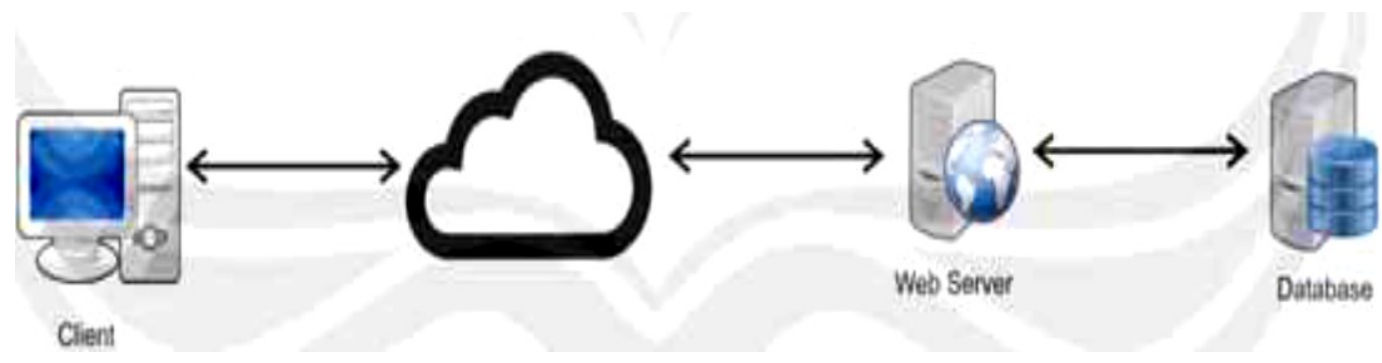

Gambar 4. Ilustrasi Web Server

\section{E. Sound Level Meter}

Sound LevelMeter (SLM) adalah alat standar untuk mengukur intensitas kebisingan. Prinsip kerjaalat tersebut adalah dengan mengukur tingkat tekanan bunyi. Tekanan bunyi adalah penyimpangan dalam tekanan atmosfir yang disebabkan oleh getaran partikel udara karena adanya gelombang yang dinyatakan sebagai amplitudo dari fluktuasi tekanan. SLM menunjukkan skala $\mathrm{A}, \mathrm{B}$, dan $\mathrm{C}$ yang merupakan skala pengukuran tiga jenis karakter respons frekuensi. Skala A merupakan skala yang paling mewakili batasan pendengaran manusia dan respons telinga terhadap kebisingan. Jadi $\mathrm{dB}(\mathrm{A})$ adalah satuan tingkat kebisingan dalam kelas A, yaitu kelas yang sesuai dengan respons telinga manusia normal, sedangkan kelas B pada tingkat kebisingan sedang dan $\mathrm{C}$ pada tingkat kebisingan tinggi. Kebisingan akibat lalu lintas dan kebisingan yang dapat mengganggu pendengaran manusia termasuk dalam skala A yang dinyatakan dalam satuan $\mathrm{dB}(\mathrm{A})$. $\mathrm{dB}(\mathrm{A})$ adalah satuan tingkat kebisingan, diperoleh bila menggunakan alat ukur SLM pada filter pembobotan A, karena B dan C tidak mencerminkan hubungan yang sesuai dengan pengujian-pengujian subjektif dengan respons terhadap frekuensi SLM mendekati respons telinga. Untuk lebih jelasnya gambar karakteristik antara dB (A), dB (B) dan dB (C) dapat dilihat pada Gambar 5.

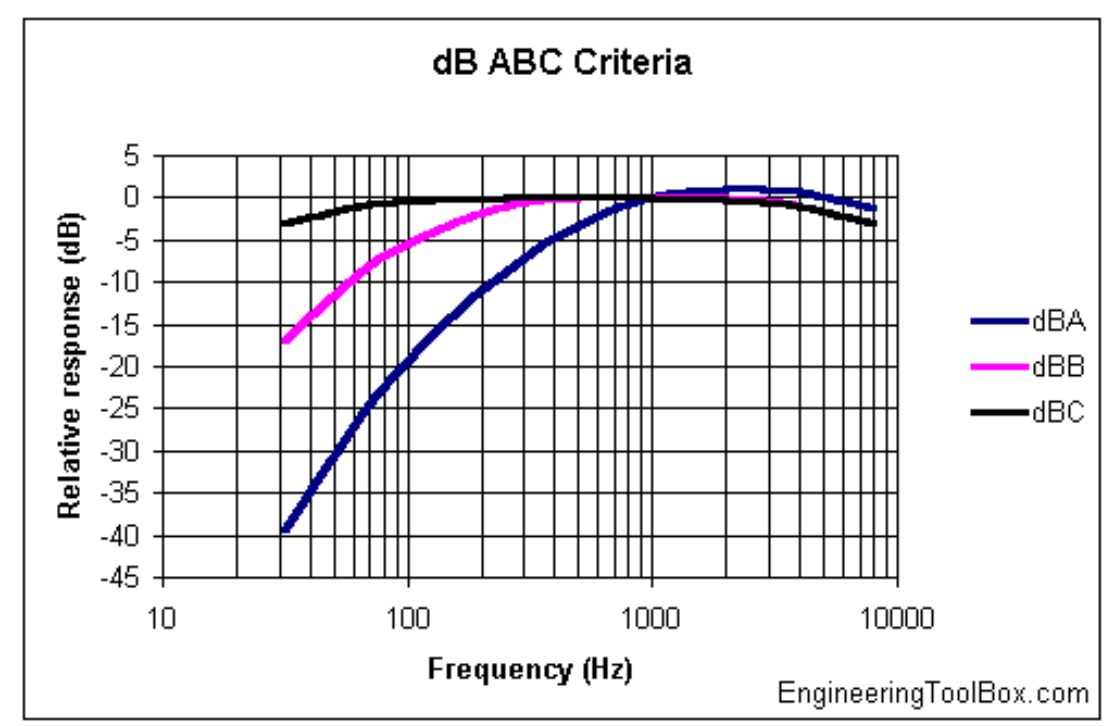

Gambar 5. Karakteristik dB (A), dB (B), dan dB (C) 


\section{Metodologi}

\subsection{Alur Penelitian}

Alur / langkah penelitian yang digunakan sebagai dasar dalam melaksanakan penelitian, ditunjukkan berdasarkan diagram alir pada Gambar 6 .

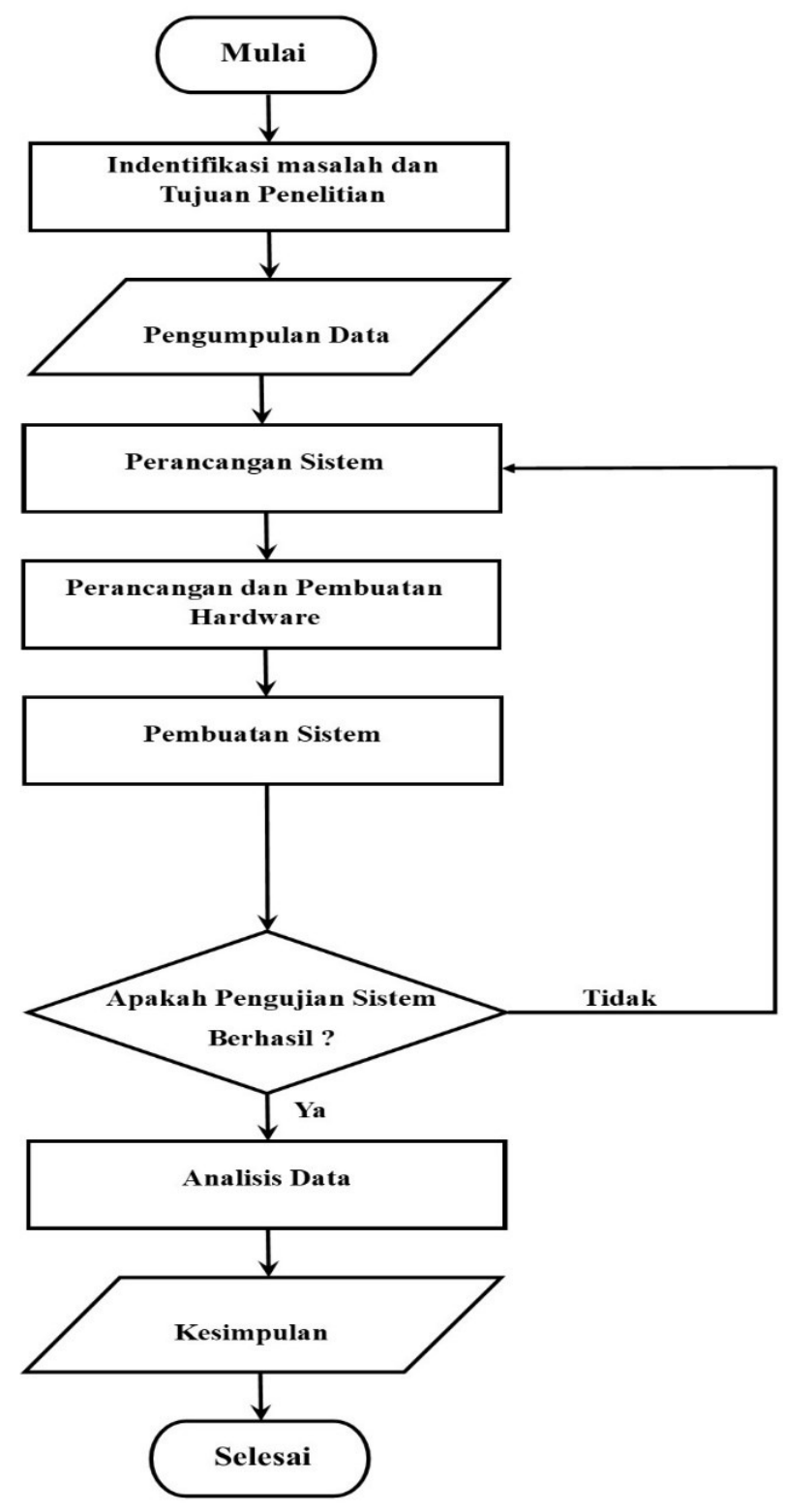

Gambar 6. Diagram Alir Penelitian

\subsection{Rancangan Sistem}

Setelah pengumpulan data yang mendukung penelitian, maka dilakukan perancangan hardware berdasarkan diagram blok pada Gambar 7. 


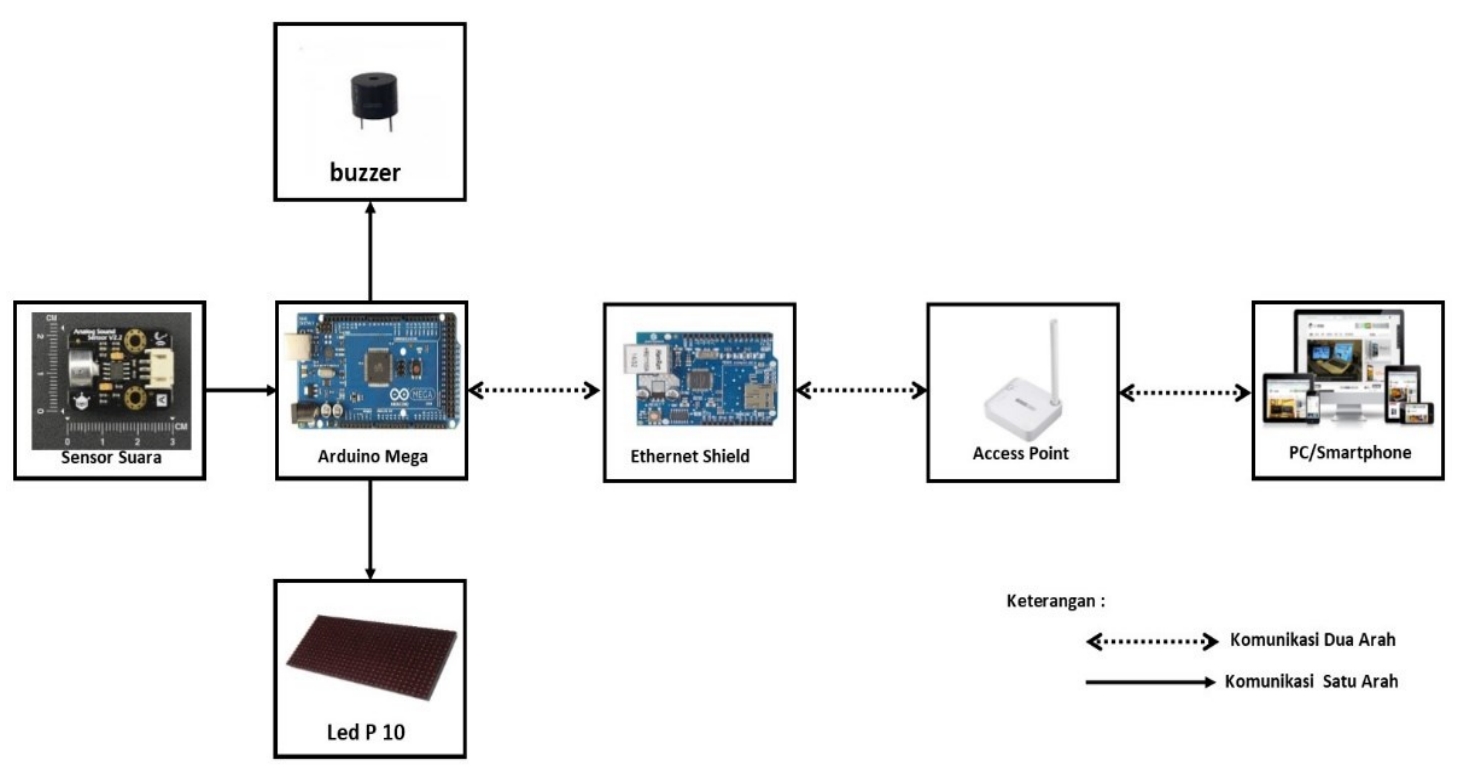

Gambar 7. Diagram Blok Perancangan Sistem

\section{Hasil Penelitian}

\subsection{High Pass Filter}

High pass filter (filter lolos tinggi) adalah filter yang nantinya hasil keluarannya hanya meloloskan frekuensi di atas frekuensi cut-off (fc). Di bawah frekuensi itu keluarannya mengecil atau idealnya tidak ada, dalam penelitian ini frekuensi cut-off (fc) sebesar $1000 \mathrm{~Hz}$. Selain itu high pass filter juga menghilangkan low frequency noise, seperti flicker noise (1/f). Biasanya high pass filter digunakan dalam instrumen yang merekam high frequency analytical signals (microphone).

Tapis lolos tinggi atau high pass filter ini dapat dibuat dengan menggunakan komponen pasif seperti resistor dengan kapasitor atau induktor. High pass filter yang dibuat dari resistor dan kapasitor disebut dengan high pass $R C$ filter. Sedangkan high pass filter atau HPF yang terbuat dari resistor dan induktor disebut dnegan high pass RL filter. Filter pasif yaitu filter yang menggunakan komponen pasif ini tidak memiliki elemen penguat seperti transistor dan op-amp sehingga tidak memiliki perolehan penguatan sinyal, oleh karena itu tingkat keluarannya selalu kurang dari tingkat masukannya. Untuk lebih jelasnya rangkaian high pass filter bisa dilihat pada Gambar 8 dan frekuensi response pada Gambar 9.

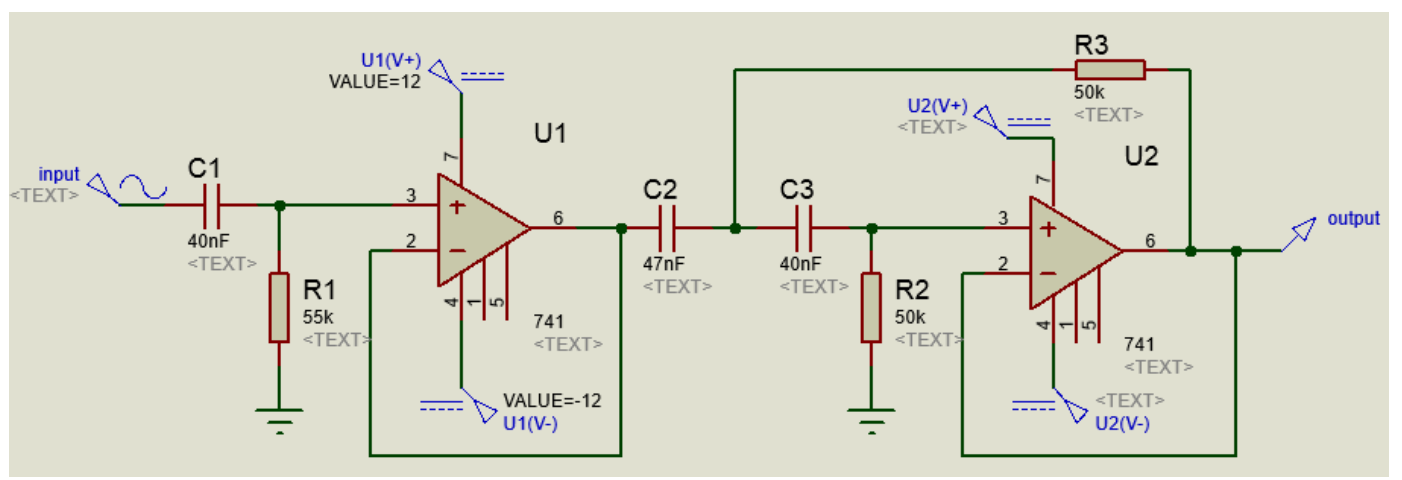

Gambar 8. Rangkaian High Pass Filter 


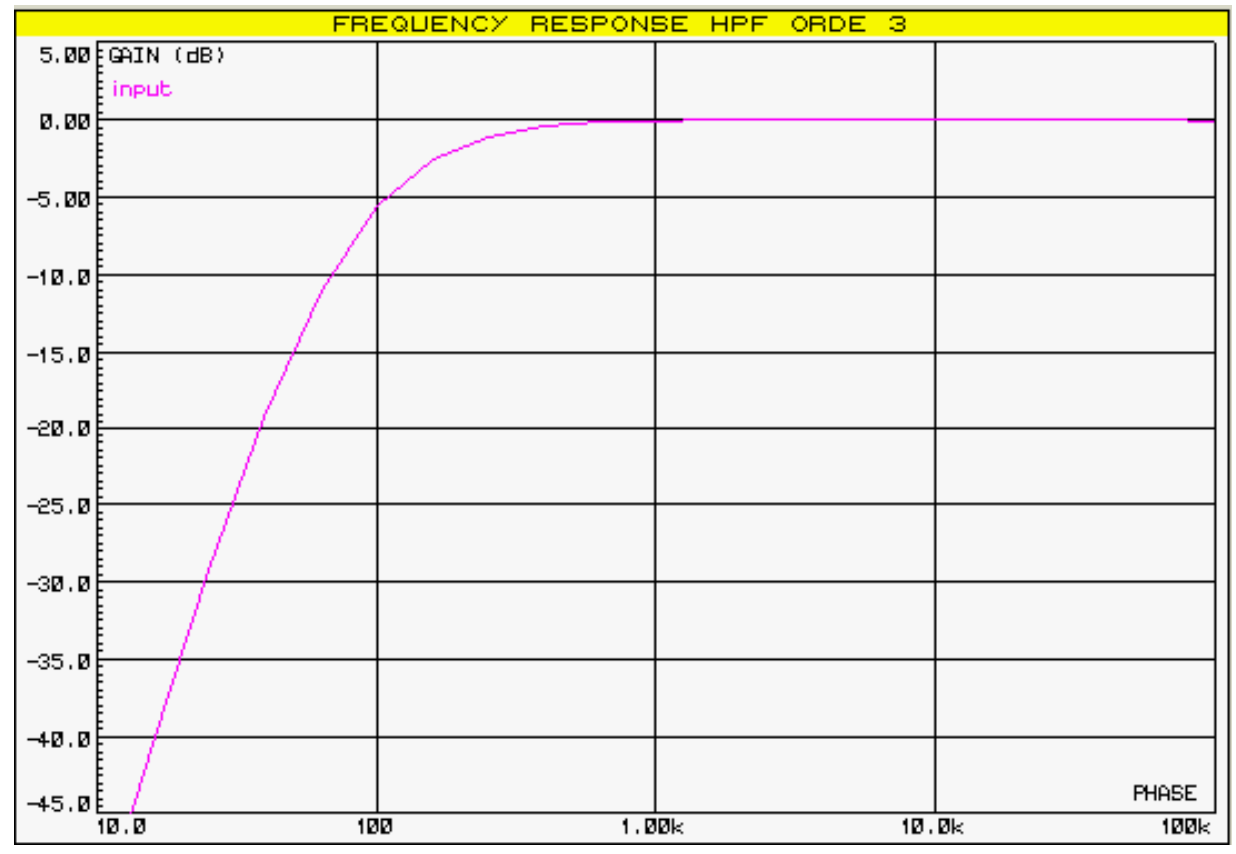

Gambar 9. Frekuensi Response High Pass Filter

\subsection{Konversi Nilai ADC ke dB}

Untuk mendapatkan nilai satuan decibel $(\mathrm{dB})$ maka diperlukan pengujian terhadap alat pendeteksi, dalam hal ini penulis menggunkan metode mapping untuk konversi nilai ADC ke dalam satuan decibel (dB). Langkah pertama yaitu pengambilan data nilai ADC, untuk memperoleh nilai ADC pengukuran dilakukan pada saat keadaan hening, penulis mengerjakan pada jam 01.00 sehinga mendapatkan nilai ADC paling kecil, yang nantinya akan digunakan sebagai konversi nilai ADC ke decibel (dB). Langkah berikutnya yaitu membandingkan alat pendeteksi kebisingan dengan alat ukur Sound Level Meter. Grafik konversi nilai ADC ke dB dilihat pada Gambar 10.

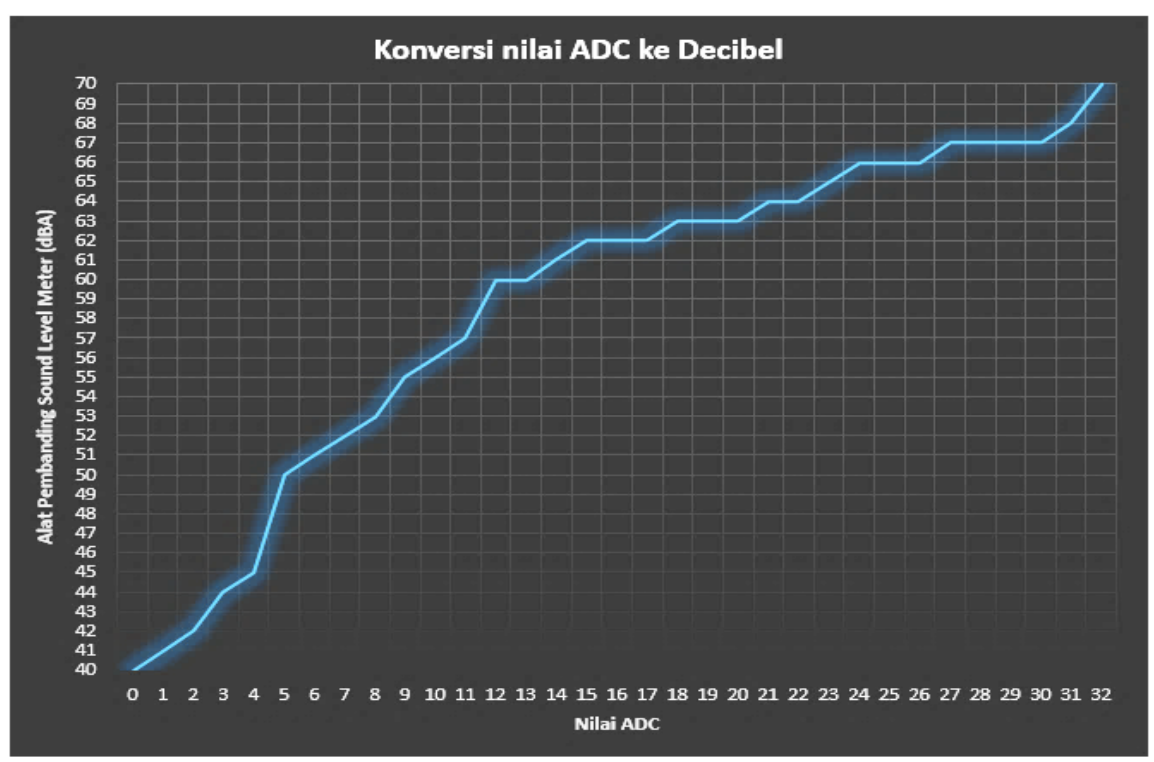

Gambar 10. Grafik Konversi Nilai ADC ke dB

Berdasarkan Gambar10, dapat ditarik kesimpulan bahwa dari pengukuran tersebut didapat nilai $\mathrm{ADC}$ dari range 0 hingga 32 pada alat pendeteksi tingkat kebisingan, dari data di 
atas dapat disimpulkan nilai $\mathrm{ADC}$ dan nilai $\mathrm{dB}$ pada alat pembanding berbanding lurus yaitu saat nilai $\mathrm{dB}$ semakin besar maka nilai $\mathrm{ADC}$ juga juga akan semakin besar. Data ini juga dapat dijadikan data konversi nilai $\mathrm{ADC}$ ke $\mathrm{dB}$ dengan memasukan data ke dalam program.

\subsection{Pembuatan Project Pada Web Server}

Untuk membuat webserver dengan Arduino, ada beberapa tambahan perangkat lainya yaitu ethernet shield yang berfungsi sebagai jembatan antara Arduino dengan TCP/IP, berikutnya router berfungsi sebagai media koneksi ke internet yang kemudian diakses melalui webbrowser. Untuk lebih jelasnya diagram blok pembuatan webserver bisa dilihat pada Gambar 11.

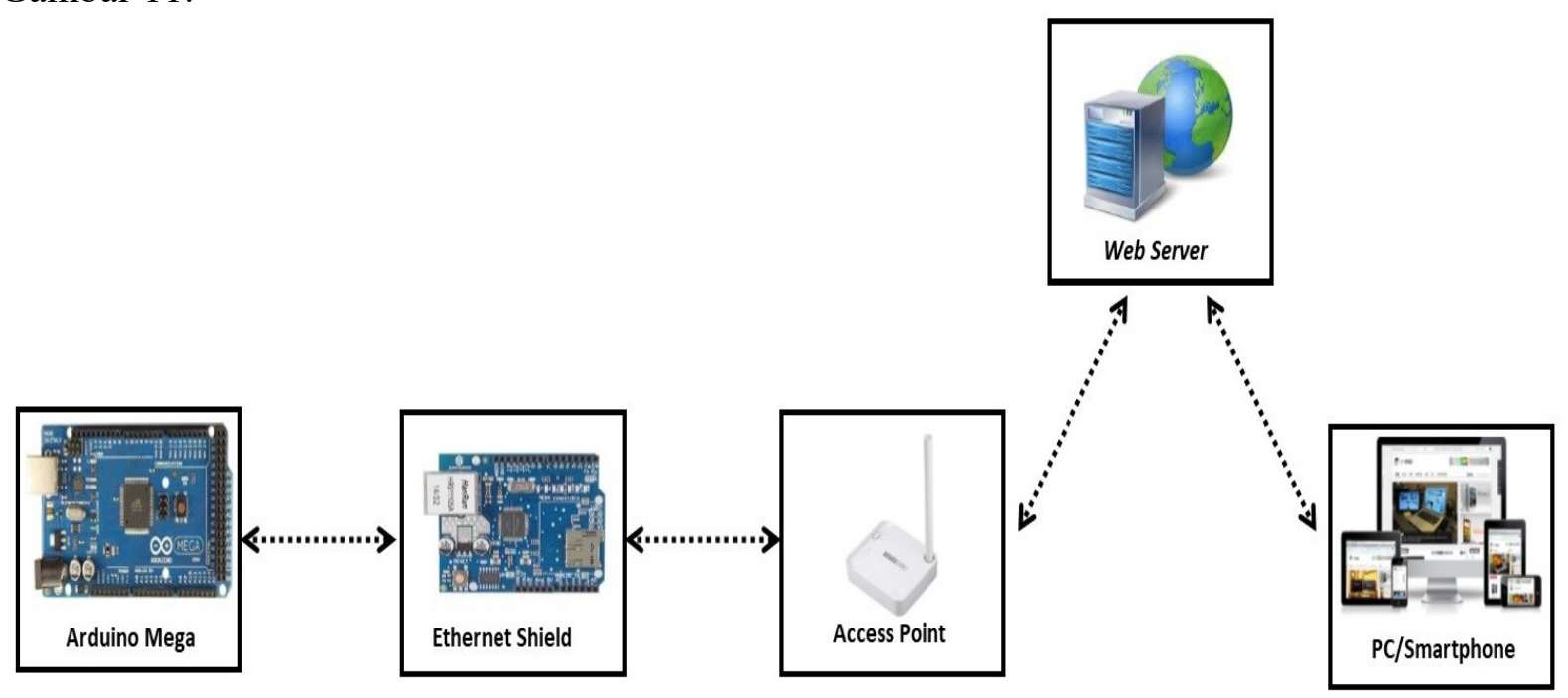

Gambar 11. Digram Blok Web Server

Dari Gambar 11 dapat dijelaskan bahwa data dari Arduino akan dikirimkan melalui jaringan internet melewati router dengan jaringan wifi, data ini akan disimpan pada webserver yang nantinya akan diakses melalui web browser yang terdapat pada laptop maupun smartphone.

Untuk menguji hardware dan software yang sudah tertanam di Arduino, hubungkan wifi laptop dengan jaringan router set IP address laptop dengan dalam satu class IP Arduino yaitu adalah 192.168.1.20 dengan demikian antara laptop dan Arduino sudah berada dalam satu class IP dan langsung bisa berkomunikasi, berikutnya buka web browser pada laptop dan tuliskan alamat IP address yaitu 192.168.1.20 maka tampilan pada web browser akan muncul seperti pada Gambar 12 dan 13. 


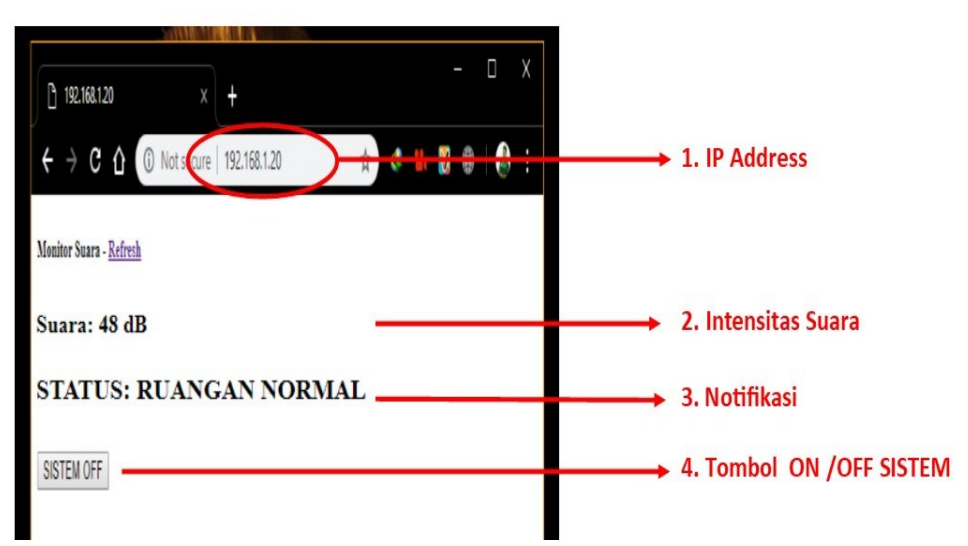

Gambar 12. Contoh Tampilan Kondisi Normal Pada Web Server

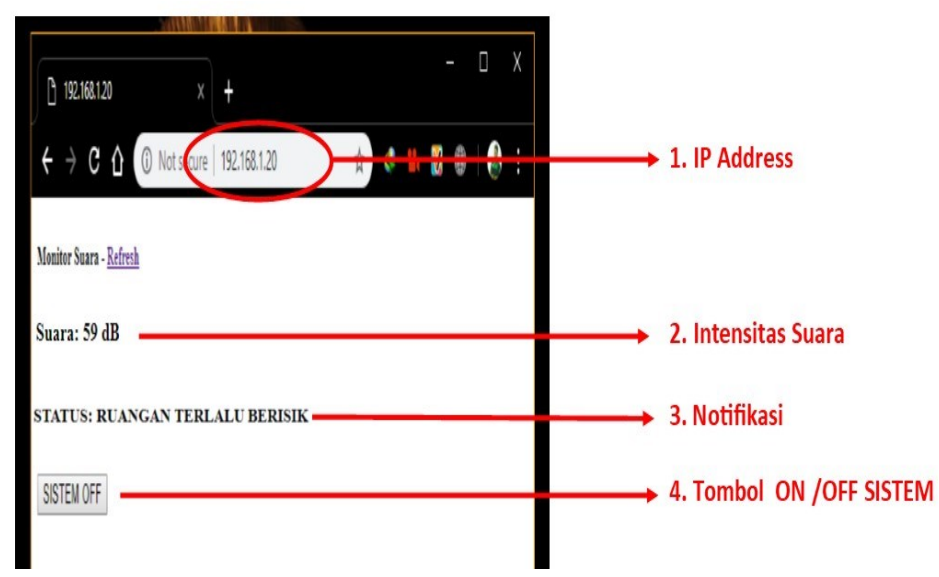

Gambar 13. Contoh Tampilan Kondisi Warning Pada Web Server

3.4 Pengujian Alat Pendeteksi Tingkat Kebisingan Dengan Alat Pembanding (Sound Level Meter)

Setelah perancangan alat dan program selesai, selanjutnya adalah tes alat pada parameter pengukuran $41 \mathrm{~dB}, 55 \mathrm{~dB}, 70 \mathrm{~dB}$ pada alat pembanding (Sound Level Meter) sebanyak 30 kali, untuk mencari nilai minimum, nilai tengah dan nilai maksimum decibel yang terdeteksi pada alat buatan. Untuk lebih jelasnya data perbandingan alat pendeteksi tingkat kebisingan dengan Sound Level Meter dapat dilihat pada Tabel 1.

Tabel 1. Hasil Perbandingan Nilai dB Pada Alat dan Sound Level Meter

\begin{tabular}{l|c|c|c|c}
\hline No & $\begin{array}{c}\text { Parameter Sound Level } \\
\text { Meter }(\mathrm{dB})\end{array}$ & $\begin{array}{c}\text { Rata- rata Alat } \\
\text { Pendeteksi }(\mathrm{dB})\end{array}$ & Simpangan & Error \\
\hline 1 & 41 & 41 & 0,4 & $0 \%$ \\
\hline 2 & 55 & 56 & 1,4 & $1,8 \%$ \\
\hline 3 & 70 & 69 & 1,6 & $1,4 \%$ \\
\hline \multicolumn{2}{|c|}{ Rata-rata Simpangan dan Error } & 1,1 & $1,06 \%$ \\
\hline
\end{tabular}

Keterangan perhitungan Tabel 1. adalah alat pendeteksi tingkat kebisingan ini dapat mengukur kebisingan di luar ruangan perpustakaan pada range rata-rata minimal $41 \mathrm{~dB}$ dan maksimal di $69 \mathrm{~dB}$ dengan nilai rata-rara simpangan 1,1 dan rata-rata error sebesar $1,0 \%$. 


\subsection{Pengujian Alat Pendeteksi Tingkat Kebisingan di Dalam Ruangan Perpustakaan}

Pengujian alat ini dilakukan di ruangan perpustakaan Sekolah Tinggi Teknologi Adisjuptipto pada ruagan berukuran 16x5 meter. Pengujian dilakukan selama 3 hari yaitu pada Senin 8 April 2019 sampai dengan Rabu 10 April 2019 pada rentang waktu pukul 09.00-15.00 WIB. Setiap rentang waktu 1 jam data akan diambil secara acak sebanyak 5 kali. Dari hasil pengujian maka didapat nilai rata-rata intensitas suara dari alat buatan pada ruangan perpustakaan Sekolah Tinggi Teknologi Adisujtipto Yogyakarta yaitu sebagai berikut :

1) Rata-rata persaman $\overline{(x)}$ pada alat buatan (Senin, 8 April 2019)

$$
\begin{aligned}
\bar{x}= & (41+44+42+58+59+53+53+60+57+59+60+57+58+59+55+57+55+60+62+ \\
& 63+62+60+55+56+56) / 25=1401 / 25=56,04 \mathrm{~dB} \\
\bar{x}= & 56,04 \mathrm{~dB}
\end{aligned}
$$

2) Rata-rata persaman $\overline{(x)}$ pada alat buatan (Selasa, 9 April 2019)

$$
\begin{aligned}
\bar{x}= & (44+42+50+65+57+50+44+57+62+67+60+50+65+52+67+62+50+42+68+ \\
& 64+50+45+61+61+70) / 25=1405 / 25=56,20 \mathrm{~dB} \\
\bar{x}= & 56,20 \mathrm{~dB}
\end{aligned}
$$

3) Rata-rata persaman $\overline{(x)}$ pada alat buatan (Rabu, 10 April 2019)

$$
\begin{aligned}
\bar{x}= & (42+45+60+65+51+68+65+45+57+52+57+44+69+64+55+63+50+52+57+ \\
& 65+64+62+57+50+53) / 25=1412 / 25=56,48 \mathrm{~dB} \\
\bar{x}= & 56,48 \mathrm{~dB}
\end{aligned}
$$

Dari hasil rata-rata pada Senin, Selasa, dan Rabu maka didapat rata-rata keseluruhan pada alat buatan yaitu sebagai berikut:

$$
\begin{aligned}
& \bar{x}=(56,04+56,20+56,48) / 3=168,72 / 3=56,24 \mathrm{~dB} \\
& \bar{x}=56,24 \mathrm{~dB}
\end{aligned}
$$

Dari nilai rata-rata tersebut, dapat disimpulkan bahwa intensitas suara yang terukur selama 3 hari berturut-turut pada ruangan perpustakaan Sekolah Tinggi Teknologi Adisutjipto Yogyakarta yaitu 56,24 dB yang artinya lebih tinggi 2,25\% dari nilai maksimum yang dianjurkan yaitu $55 \mathrm{~dB}$ (KepMenLH, 1996).

\section{Kesimpulan}

1. Sistem pendeteksi tingkat kebisingan menggunakan sensor suara ini dapat mengukur tingkat kebisingan pada range minimal $41 \mathrm{~dB}$ dan maksimal $69 \mathrm{~dB}$ dengan nilai rata-rata simpangan 1,1 dan nilai rata-rara error sebesar $1,0 \%$.

2. Intensitas suara yang terukur oleh alat pendeteksi tingkat kebisingan pada ruangan perpustakaan Sekolah Tinggi Teknologi Adisjutjipto Yogyakarta yaitu sebesar 56,24 dB yang artinya lebih besar $2,25 \%$ dari nilai maksimum yang dianjurkan yaitu $55 \mathrm{~dB}$. 


\section{Daftar Pustaka}

[1] Arduino Mega2560. https://www.arduino.cc/en/Guide/ArduinoMega2560. Diakses pada 14 Desembar 2018.

[2] Ethernet Shield. https://www.arduino.cc/en/Guide/ArduinoEthernetShield. Diakses pada 14 Desember 2018.

[3] Hisam, Ahmad. 2019. Perancangan Dan Pembuatan Alat Pendeteksi Tingkat Kebisingan Bunyi Berbasis Mikrokontroler. FMIPA ITS. Surabaya.

[4] Kharis, 2013. Rancang Bangun Sistem Deteksi Kebisingan Sebagai Media Kontrol Kenyamanan Ruangan Perpustakaan Skripsi, Program Studi Fisika Fakultas Sains dan Teknologi, Universitas Islam Negeri Sunan Kalijaga Yogyakarta.

[5] Kurniawan, 2016. Purwa Rupa IoT (Internet Of Things) Kendali Lampu Gedung Skripsi, Fakultas Teknik, Universitas Lampung Bandar Lampung.

[6] Menteri Negara Lingkungan Hidup. 1996. Keputusan Menteri Negara Lingkungan Hidup Nomer : Kep-48/MENLH/11/1996 Tentang Baku Tingkat Kebisingan.Jakarta.

[7] Menteri Tenaga Kerja. 1999. Keputusan Menteri Tenaga Kerja Nomor :Kep51/Men/1999 Tentang Nilai Ambang Batas Faktor Fisika Di Tempat Kerja. Jakarta.

[8] Nengsih, Ayu Gusthia. 2016. Alat Deteksi Kebisingan Pada Perpustakaan Menggunakan Mikrokontroler Arduino Dan Sms Gateway Skripsi, Jurusan Teknik Elektro, Politeknik Negeri Padang.

[9] Nasri, Syahrul M. 1997 Teknik Pengukuran Dan Pemantaun Kebisingan di Tempat Kerja. Universitas Indonesia. Jakarta.

[10] Sandi, Brata Mela 2015. Perancangan Running Text Display Menggunakan Modul TFS5UR Sebagai Media Pembelajaran Untuk Meningkatkan Kemampuan Membaca Cepat Kelas V SDN 02 PAIT Skripsi, Jurusan Pendidikan Teknik Elektro, Fakultas Teknik, Universitas Negeri Semarang.

[11] Sasongko, dkk. 2000. Kebisingan Lingkungan. Badan Penerbit Universitas Diponegoro. Semarang.

[12] Setiawan, Iwan 2019. Buku Ajar Sensor Dan Transduser. Fakultas Teknik Universitas Diponegoro. Semarang. 